\title{
Human Health Benefits of the Minamata Convention on Mercury
}

\author{
Yanxu Zhang ${ }^{1, *}$, Stephanie Dutkiewicz ${ }^{2}$, Huanxin $\mathrm{Zhang}^{3,4}$, Shiliang $\mathrm{Wu}^{4,5}$, Long \\ Chen $^{6}$, Shuxiao Wang ${ }^{7,8}$, Ping Li $^{9}$, Feiyue Wang ${ }^{10}$
}

${ }^{1}$ Joint International Research Laboratory of Atmospheric and Earth System Sciences, School of Atmospheric Sciences, Nanjing University, Nanjing, 210023, China

${ }^{2}$ Department of Earth, Atmospheric and Planetary Sciences, Massachusetts Institute of Technology, Cambridge, Massachusetts, USA

${ }^{3}$ Department of Chemical and Biochemical Engineering, University of Iowa, Iowa City, Iowa, USA

${ }^{4}$ Geological and Mining Engineering and Sciences, Michigan Technological University, Houghton, Michigan, USA

${ }^{5}$ Civil and Environmental Engineering, Michigan Technological University, Houghton, Michigan, USA

${ }^{6}$ Key Laboratory of Geographic Information Science (Ministry of Education), School of Geographic Sciences, East China Normal University, Shanghai 200241, China

${ }^{7}$ School of Environment, State Key Joint Laboratory of Environment Simulation and Pollution Control, Tsinghua University, Beijing 100084, P. R. China

${ }^{8}$ State Environmental Protection Key Laboratory of Sources and Control of Air Pollution Complex, Beijing 100084, P. R. China

${ }^{9}$ State Key Laboratory of Environmental Geochemistry, Institute of Geochemistry, Chinese Academy of Sciences, Guiyang, China

${ }^{10}$ Centre for Earth Observation Science, Department of Environment and Geography, University of Manitoba, Winnipeg, MB R3T 2N2, Canada

*Corresponding to: Yanxu Zhang, zhangyx@nju.edu.cn

\begin{abstract}
The Minamata Convention is a legally-binding international treaty aimed at reducing the anthropogenic release of mercury, a potent neurotoxin. However, its human health benefit has not been quantified on a global scale. Here we evaluate the Convention's benefit by a coupled climate-atmosphere-land-ocean-ecosystem model and a human mercury exposure component that considers all food categories. We find the mercury health risk decreases nonlinearly with emission reduction, and the most optimistic scenario leads to mercury level in marine biota half of the present-day level. Our results show that the accumulated benefits of the Convention are 660 billion USD avoided earn loss (3\% discount rate, realized in 2010) and 1.2 million avoided deaths from fatal
\end{abstract}


heart attacks over the period 2010-2100, with substantial global human health cost if delaying emission reduction actions. Such a comprehensive modeling approach helps parties to evaluate the effectiveness of implementation as required by the Convention.

\section{Introduction}

Mercury $(\mathrm{Hg})$ is a global pollutant that is associated with impaired neurocognitive deficits in human fetuses and cardiovascular effects in adults (Axelrad et al. 2007; Roman et al. 2011). Human exposure to mercury is predominately via the consumption of food (e.g., seafood and rice) that contain methylmercury ( $\mathrm{MeHg}$ ), the most toxic form of mercury (Bellanger et al. 2013). The annual death from the fatal heart attack that is attributable to $\mathrm{MeHg}$ exposure is estimated to over 10,000 in China and the U.S. Economic losses from intelligence quotient (IQ) decrease of developing brains associated with MeHg exposure has been estimated at $\$ 16$ billion in the U.S. and the European Union (Chen et al. 2019; Bellanger et al. 2013; Grandjean et al. 2012). To protect human health, the Minamata Convention on Mercury (hereinafter refer to as the Convention), a legally-binding international treaty, took effect in August 2017 to reduce anthropogenic emissions of mercury (Pacyna et al. 2016). A periodic effectiveness evaluation is required by the Convention (H. Selin 2014), however, the benefit of the projected emission reduction associated with the Convention to human exposure of $\mathrm{MeHg}$ has not been properly evaluated.

Mercury in the environment is from both natural sources such as volcanic emissions and anthropogenic sources such as coal burning, artisanal gold mining, metal smelting, and release from products that contain $\mathrm{Hg}$ (N. E. Selin et al. 2008; Horowitz et al. 2014). The re-emissions from soils and oceans that receive past atmospheric depositions of $\mathrm{Hg}$ (a.k.a. legacy emissions) are also important sources with magnitude 2-3 times larger than the primary emissions (N. E. Selin et al. 2008; Horowitz et al. 2017). The MeHg exposure is influenced by a chain of processes including atmospheric emission, atmospheric transport and deposition, airsea exchange, air-land exchange, chemical transformation, food web transfers, and human food intake (Giang and Selin 2016). These processes are modulated by the fluctuation and change in climate, land-use, ocean circulation, and ecosystem functions (Schartup et al., n.d.; H Zhang, Holmes, and Wu 2016). Earlier studies do not link emissions to exposure changes (Trasande, Landrigan, and Schechter 2005; Spadaro and Rabl 2008; Rice, Hammitt, and Evans 2010; Bellanger et al. 2013; Griffiths, McGartland, and Miller 2007). Later efforts in global $\mathrm{Hg}$ exposure modeling have considered only a subset of these processes. For instance, using atmospheric transport models, atmospheric deposition is considered as an indicator for the level of MeHg in seafood (Giang and Selin 2016; H Zhang, Holmes, and Wu 2016; Chen et al. 2019). Zhang et al. (H Zhang, Holmes, and Wu 2016) however did included the impact of climate, land-use and land-cover changes on atmospheric transport and deposition and Amos et al. (Amos et al. 2013) considered the response of land/ocean re-emissions to anthropogenic emission change with a box model.

In this study, we develop a more comprehensive approach to project the change in human $\mathrm{MeHg}$ exposure responding to emission control. We integrate changes in anthropogenic emissions, climate change, environmental processes (atmospheric transport and deposition, air-sea exchange, land-air exchange, terrestrial processes, oceanic transport and transformation), and marine ecosystem change. The MeHg levels in the environment are used to scale an intake inventory of $\mathrm{MeHg}$ for different countries, which are further used to calculate the human health impact based on epidemiology-based dose-response relationships. We present a map 
of MeHg-related health risks for all the countries for the first time. Based on this, we translate future $\mathrm{Hg}$ emission policies into impacts on human health risk, and to help parties and stakeholders to evaluate impacts from changes in emissions and effectiveness evaluation of the Convention.

\section{Results and Discussion}

Baseline Hg-related health risk. We estimate that the global health impacts associated with $\mathrm{MeHg}$ exposure are 34 billion USD economy loss (2008 value and adjusted by purchasing power parity, PPP) from 7.7 million points of IQ decrements ( 0.058 point per-fetus) and 24,000 deaths per year at present-day (2010). We include two health endpoints as a consequence of food $\mathrm{MeHg}$ exposure: decrement in IQ of newborns and fatal heart attack (FHA) for general populations. The IQ decrement is transferred to lifelong earn loss based on the projections of population and economic growth of each country (Bellanger et al. 2013). The exposure from seafood, freshwater fish, and rice consumption is included here with the $\mathrm{MeHg}$ concentrations scaled by planktonic $\mathrm{MeHg}$ concentrations (for seafood) and atmospheric $\mathrm{Hg}$ deposition (for the latter two) (see method for more details).

We find that the population dietary choices are vital factors influencing $\mathrm{MeHg}$ exposure and health risk. Coastal countries with large marine fish consumption have the largest $\mathrm{MeHg}$ exposure, and rice and freshwater fish consumptions are not negligible in some countries (Figure 1). The highest per-fetus IQ decrements are found in countries with large seafood consumption, such as Maldives (1.0 point), Iceland ( 0.48 point), Kiribati (0.41 point), and Malaysia ( 0.28 point) (Figure 1A). The national average per-capita seafood consumptions are 190 $\mathrm{kg} / \mathrm{y}, 89 \mathrm{~kg} / \mathrm{y}, 74 \mathrm{~kg} / \mathrm{y}$, and $48 \mathrm{~kg} / \mathrm{y}$ for these four countries, respectively, which are much higher than the global average of $15 \mathrm{~kg} / \mathrm{y}$. The lowest risk is found in inland countries with smaller seafood consumption, such as Ethiopia ( 0.00088 point), Chad ( 0.0043 point), and Malawi ( 0.0072 point). Another important factor is the level of $\mathrm{Hg}$ in atmospheric deposition, which is assumed to drive the variability in $\mathrm{MeHg}$ concentrations in land food (rice and freshwater fish) (Chen et al., 2019). Highly polluted regions such as East Asia have generally higher $\mathrm{MeHg}$ exposure risks. For instance, Bangladesh, Cambodia, China, and Laos have the largest MeHg risk derived from land food exposure. The contribution of rice to $\mathrm{MeHg}$ exposure has previously been found for communities relying on rice grown in sites heavily contaminated with $\mathrm{Hg}$ (Hua Zhang et al. 2010; Rothenberg, Windhammyers, and Creswell 2014), but our findings highlight the potential importance of rice consumption for general populations. We find the contribution from rice could be dominant over inland countries with large rice consumptions, e.g. Nepal (86\%), Laos (59\%), and Bangladesh (49\%).

Figure 1B shows the economic loss of countries due to IQ reduction of newborns, which causes loss of productivity and thus a lower earning potential (Rice and Hammitt 2005). The distribution among countries reflects their MeHg exposure, population, and income level. The US ranks first by losing 6.3 billion USD per year, followed by China (4.8), Japan (3.5), and France (1.5). Europe as a whole has a total loss of 7.2 billion USD. The spatial pattern of the deaths associated with fatal heart attacks (Figure 1C) is similar to that of the perfetus IQ decrement but also influenced by the total population and baseline fatal heart attack incidence. The largest numbers of deaths are from populous countries with mild to high per-capita risks, such as China $(5,400)$, Indonesia (2,400), India (2,200), and Russia (1,600).

The modeled spatial pattern agrees with the distribution of $\mathrm{Hg}$ biomarkers in human populations. For instance, South Korea had the highest blood Hg concentrations among nine studied countries. Western Pacific, eastern Mediterranean, and Southeast Asia are also found with higher blood Hg levels than Africa, America, and 
Europe (Basu et al. 2018). Our results for the Chinese population (0.088 point IQ decrease per fetus and 5400 FHA deaths) are lower than Chen et al. (Chen et al. 2019) (0.14 points per fetus and 7360 deaths), as we exclude food $\mathrm{MeHg}$ concentration data for contaminated sites. We estimate a total of 334,000 points per year of IQ decrements in the US, which is close to previous estimates (264,000-285,000 points per year) (Bellinger 2012; Grandjean et al. 2012). Our estimate (560,000 points) for Europe is slightly lower than Bellinger et al. (Bellanger et al. 2013), who calculated 640,000 points of IQ loss based on hair Hg concentrations among women of reproductive age.

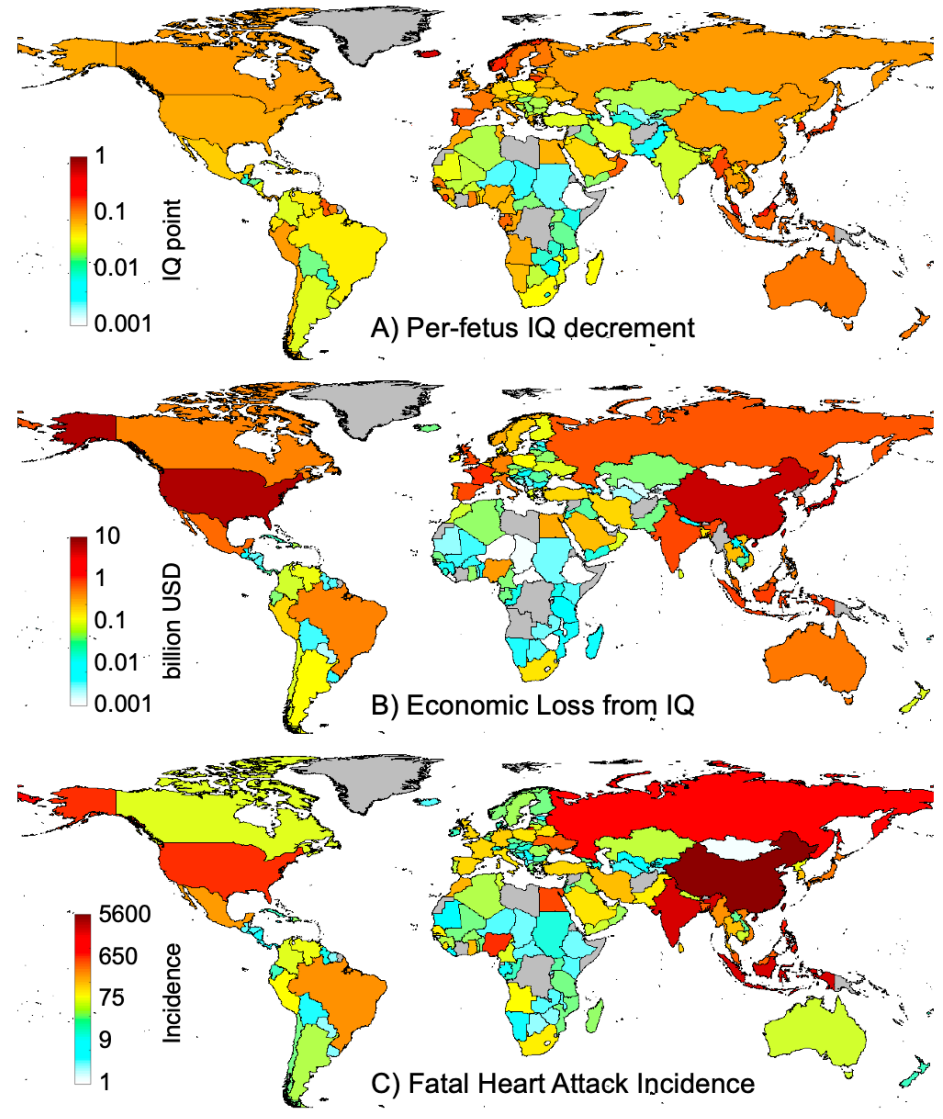

Figure 1. Global health impact of $\mathrm{MeHg}$ food exposure at present-day. A) Per-fetus IQ point loss B) National total economic loss in billion US dollars (2008 value and PPP adjusted) and C) National total fatal heart attack incidence. Grey area indicates missing data.

Future Hg emissions. Figure 2 shows our projections of global anthropogenic $\mathrm{Hg}$ emissions in the 21st century as a result of implementing the Minamata Convention. The global total anthropogenic emissions are $1890 \mathrm{Mg}$ $\mathrm{yr}^{-1}$ in 2010 with artisanal and small-scale gold mining (ASGM, 37\%) and fossil fuel combustion (25\%) as the largest two sources followed by non-ferrous metals production (10\%) and cement production (9\%) (AMAP/UNEP 2013). The emissions are projected to decrease to $1020 \mathrm{Mg} \mathrm{y}^{-1}$ in 2035 (scenario S4 in Figure 2) (Pacyna et al. 2016). Part of the emission reduction is from fossil fuel combustion and cement production resulting from the co-benefits of greenhouse gas emission control. Assuming a full implementation of the Convention, the $\mathrm{Hg}$ emissions from $\mathrm{Hg}$-containing products are projected to reduce by $70 \%$ in 2035 compared to the 2010 situation, and the use of Hg in ASGM is reduced by 46\% (Pacyna et al. 2016). In 2050, further emission reductions are assumed as per the Convention. We project global emissions of $300 \mathrm{Mg} \mathrm{y}^{-1}$ in 2050 with 
the $\mathrm{Hg}$-containing product and ASGM emissions reduced by $95 \%$ and $76 \%$, respectively. The maximum feasible reduction technologies are assumed for the industrial and energy sectors. This projection is the same as the maximum possible emission reduction scenario without constraints in the economy and increasing demand in 2035 by (Pacyna et al. 2016). Although it was considered an unrealistic scenario for 2035 (Pacyna et al. 2016), we treat it as an optimistic projection for 2050. In 2100, we expect a further emission reduction as per the Convention due to continuous technology advance in emission control, "greener" energy structure, and completely phasing-out of ASGM and Hg-containing products. We subsequently assume a close to zero global anthropogenic $\mathrm{Hg}$ emission in 2100, or a world with negligible anthropogenic emissions compared to reemissions from soil and ocean as legacy emissions. As a reference, a close to constant emission scenario (except a slight increase of emissions to $1960 \mathrm{Mg} \mathrm{yr}^{-1}$ in 2035) is considered (S1). This assumes that the increase in emission activity is balanced by the decrease of emission factors due to continuous emission control (Pacyna et al. 2016).

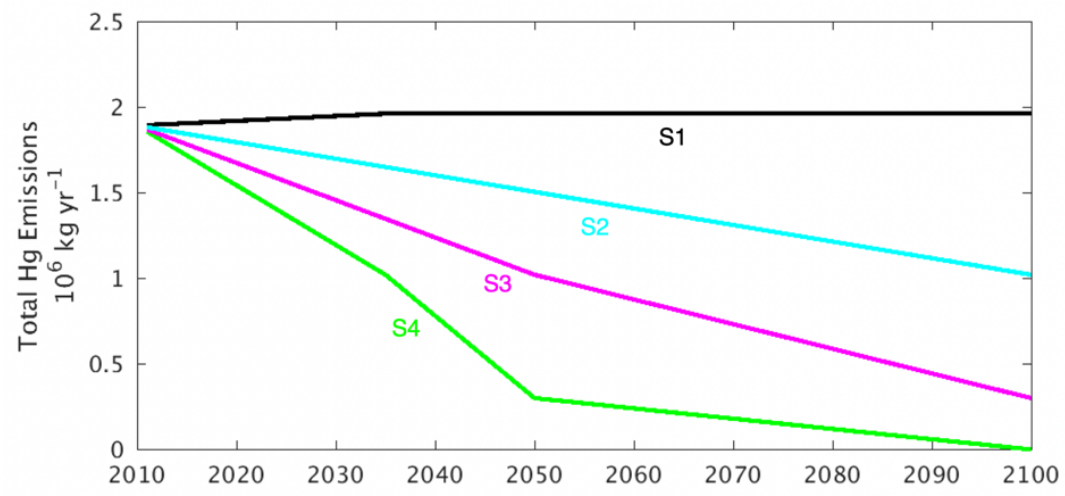

Figure 2. Projections of global total anthropogenic emission of $\mathrm{Hg}$ during 2010-2100 due to the Minamata Convention based on different emission scenarios(Pacyna et al. 2016). S1 stands for a close to constant emissions, and S4 is an optimistic scenario with zero emissions in 2100. S3 postpones the 2035 and 2050 targets for S4 to 2050 and 2100, respectively, while S2 postpones the 2030 target for S4 to 2100.

The Response of environment levels. We find that reduced $\mathrm{Hg}$ emissions substantially reduce atmospheric $\mathrm{Hg}$ deposition levels in the future (Figure 3). The atmospheric transport and deposition are simulated by the GEOSChem model driven by the meteorological data from the GISS ModelE2 model (see Methods for more details). The model shows higher deposition over source regions (e.g. East Asia, West Europe, and North America), regions covered with forests that have larger dry deposition velocity (e.g., South America), and over ocean regions with high precipitations (Figure 3B). We find the $\mathrm{S} 4$ scenario reduces the atmospheric deposition by $37 \%$ and 54\% in 2100 (Figure 2A), compared to a slight increase of 3-5\% for the S1 scenario. Overall, the decrease of deposition is smaller than that of anthropogenic emissions (Figure 2) because the latter only accounts for 20$30 \%$ of total atmospheric emissions (Horowitz et al. 2017). The change in deposition for different regions is predicted to be fairly uniform (e.g. $49-63 \%$ in 2100 , Figure $3 \mathrm{~J}$ ). 


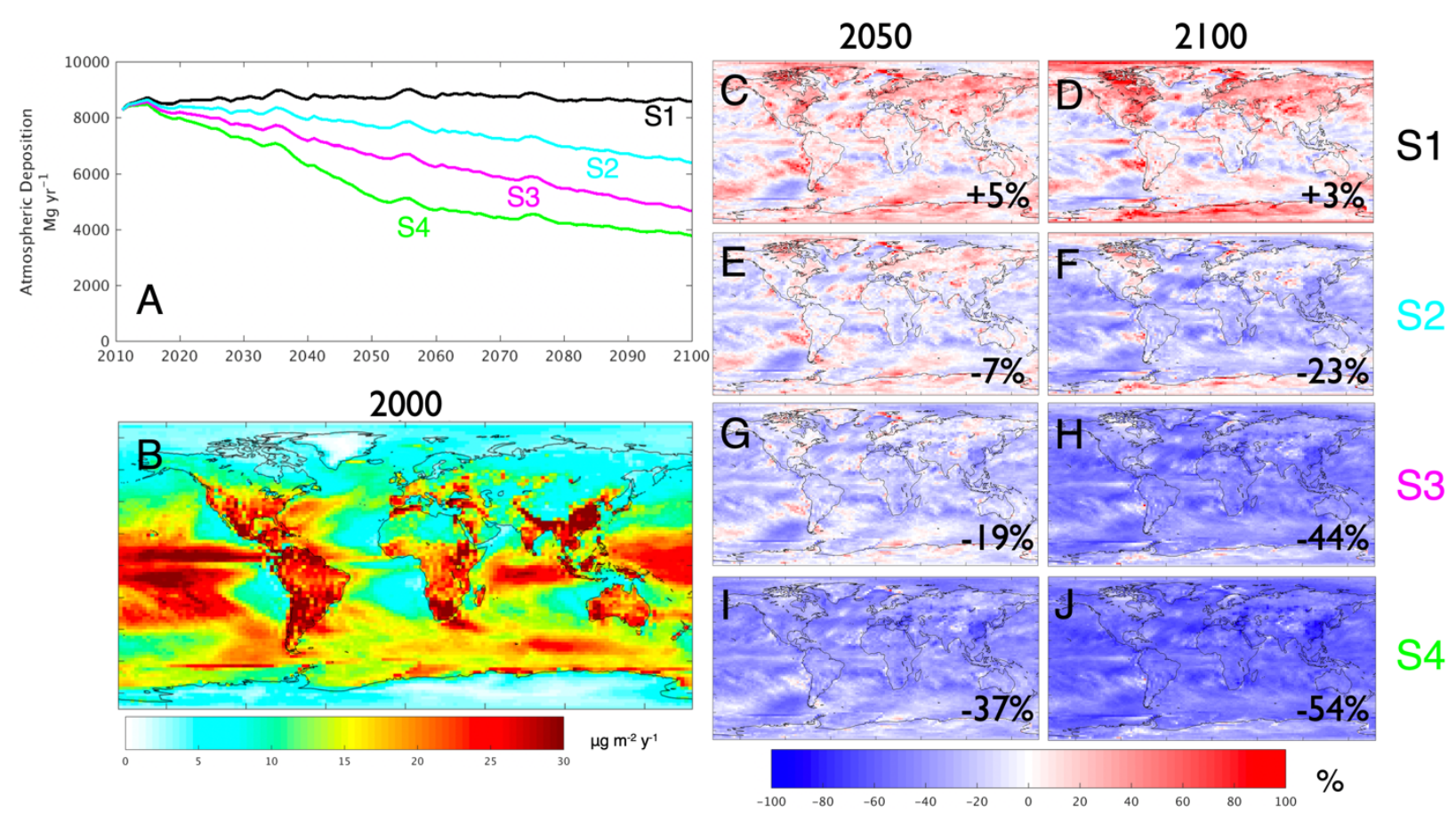

Figure 3. Projected atmospheric $\mathrm{Hg}$ deposition. A) Change of global average; B) Spatial distribution at the present-day (2010); C-J) Percentage changes in 2050 and 2100 for the four emission scenarios relative to the present-day values.

Contrasting with previous modeling results (Giang and Selin 2016; Chen et al. 2019), we find that the plankton $\mathrm{MeHg}$ concentrations do not respond proportionally to atmospheric deposition in the future (Figure 4). The ocean $\mathrm{Hg}$ cycle is simulated by the MITgcm model driven by ocean physics data from the IGSM Earth System Model. The model is coupled with a marine plankton ecosystem model (DARWIN) and the GEOS-Chem model (refer to the method for more details). Higher concentrations are modeled over productive regions (e.g. high-latitudes and the eastern tropical oceans) (Figure 4B). The S4 scenario results in a $28 \%$ and $49 \%$ decrease in planktonic MeHg in 2050 and 2100, respectively (Figure 4A). This is associated with the relatively long lifetime of MeHg in the subsurface ocean (Blum et al. 2013; Sunderland et al. 2009; Y. Zhang et al. 2020). The upwelling from this pool cancels the decreasing trend in the planktonic $\mathrm{MeHg}$ concentrations in the surface ocean. This highlights the importance of oceanic processes in projecting the benefits of emission reduction policies, which are often neglected in previous studies (Giang and Selin 2016; Chen et al. 2019). 


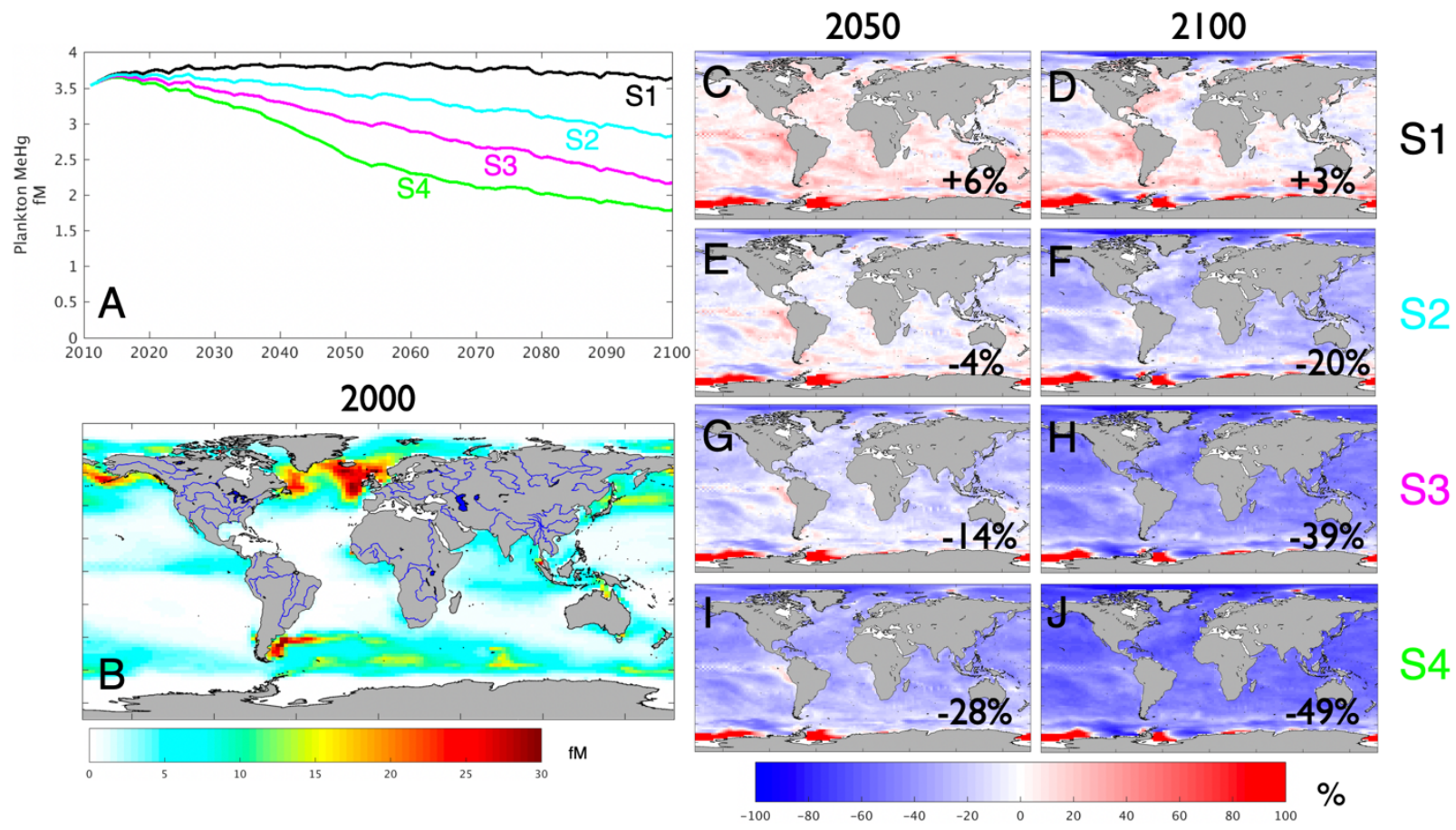

Figure 4. Projected ocean plankton $\mathrm{MeHg}$ concentrations. A) Change of global average; B) Spatial distribution at the present-day; C-J) Percentage change in 2050 and 2100 for the four emission scenarios relative to the present-day values.

Impact of climate change. As shown in Figure 3C and 3D, The increased deposition predicted by the S1 scenario (i.e. constant anthropogenic emission) results from the constantly increased legacy $\mathrm{Hg}$ pool in the soil and subsurface ocean (Amos et al. 2013). We find the level of increase is smaller than previous modeling results that do not take into account climate change (N. E. Selin 2018; Amos et al. 2013). Indeed, warmer temperatures in future climate could suppress elemental $\mathrm{Hg}$ oxidation by bromine atom, which reduces oxidized $\mathrm{Hg}$ concentrations by $20-30 \%$ in 2100 and subsequent deposition. This result illustrates that climate-induced change in atmospheric chemistry can partially offset the impact of increased legacy emissions on atmospheric $\mathrm{Hg}$ deposition. Our model also shows a large regional variability for atmospheric deposition in the future under the S1 scenario. Overall, the deposition is increased over high-latitude regions in both hemispheres and the equatorial regions but decreased in mid-latitude regions. This is largely associated with the change in precipitation as modeled by the GISS model, as wet deposition dominates the total atmospheric deposition of Hg.

The global average plankton $\mathrm{MeHg}$ concentrations are projected to increase slightly by $6 \%$ and $3 \%$ under scenario S1 for 2050 and 2100, respectively (Figure 4C and 4D). We also find that the changing pattern in plankton $\mathrm{MeHg}$ is spatially decoupled with that of atmospheric deposition. Indeed, the seawater $\mathrm{MeHg}$ is not only influenced by the atmospheric input of inorganic mercury as a substrate, but also by processes such as $\mathrm{MeHg}$ formation and degradation, as well as plankton biomass. In 2100, the plankton $\mathrm{MeHg}$ concentrations in the Arctic and the Southern Ocean are projected to decrease by $-9.8 \%$ and $-2.9 \%$, respectively, while the atmospheric deposition is predicted to increase in these regions (Figure $3 \mathrm{C}$ and $3 \mathrm{D}$ ). The increase in temperature accelerates $\mathrm{MeHg}$ degradation that drives the decrease in plankton $\mathrm{MeHg}$ over these regions. Over tropical and mid-latitudes, the effect of temperature on $\mathrm{MeHg}$ degradation becomes less important, but the change in ocean 
primary production and subsequent $\mathrm{MeHg}$ formation matters (Y. Zhang et al. 2020; S. Dutkiewicz, Scott, and Follows 2013). This shows the importance of process-based models in predicting the response of the $\mathrm{Hg}$ level to climate change.

Other scenarios. As no quantitative reduction targets for $\mathrm{Hg}$ emissions are set by the Convention, the actual emissions vary substantially due to different implementation choices for countries, such as defining technological options and advancing phaseout dates (N. E. Selin 2018). Considering the scenario S4 described above as a best or most optimistic case, we include two more scenarios to bracket the uncertainty of future emissions following (N. E. Selin 2018) (Figure 2). In scenario S3, the 2035 and 2050 targets of S4 are postponed to 2050 and 2100, respectively. In scenario S2, the 2035 target is proposed to 2100 .

We find the modeled deposition would decrease by $6.8 \%$ under the S2 scenario in 2050, given a $20 \%$ decrease in anthropogenic emissions. This contrasts the findings of Amos et al. (2013) that a more aggressive $\mathrm{Hg}$ emission decreasing pathway is required to bring down atmospheric deposition. Indeed, we observed a decrease in atmospheric deposition in North America and West Europe in the past three decades, responding to a $\sim 30 \%$ decrease in global total anthropogenic emissions (Y. Zhang et al. 2016). Overall, S2 and S3 assume emission reduction of 20-46\%, and the resulted deposition would decrease by $7-19 \%$ (Figure 3). Similar patterns are found for 2100. A conceptual model was proposed that the decline of $\mathrm{Hg}$ in marine biota would take much longer than the decrease in Hg emissions (Wang et al. 2019). Our study confirms this hypothesis and finds that the percentage changes in planktonic MeHg concentrations for S2, S3, and S4 in 2050 (4\%, 14\%, and 28\%, respectively) are much smaller than those of deposition (7\%,19\%, and 37\%) and anthropogenic emissions (20\%, $46 \%$, and $85 \%$ ). The spatial patterns of changes of S2 and S3 reflect a transition from climate impact (S1) to emission dominance (S4).

Health benefits. Without the Convention, the health impact will increase to 140 billion USD economy loss (2008 USD adjusted by PPP, no discount) from 6.4 million points of IQ decrements and 34,000 deaths per year in 2100 (scenario S1). Figure 4 shows the projected global human health benefits by the Convention during 2010-2100, which are calculated as the difference of health risk between the baseline scenario S1 and the other three (S2-S4). The accumulated health benefits during 2010-2100 for S4 are projected to be 660 billion USD (3\% discount rate, realized in 2010, same hereinafter) and 1.2 million avoided deaths from FHA. Postponing the 2035 target to 2050 decreases the benefit to 450 billion USD and 0.80 million avoided deaths (S3). To further postpone the 2035 target to 2100 results in an even smaller benefit of 240 billion USD and 0.43 million avoided deaths (S2). We find that the projected IQ decrements and avoided deaths increase slower after 2050, especially for S4, reflecting the level off of atmospheric $\mathrm{Hg}$ deposition and plankton $\mathrm{MeHg}$ levels (Figures 3 and 4). The $\mathrm{Hg}$ cycling in the environment by then is dominated by legacy sources, thus reducing anthropogenic emissions has little effect on the environmental Hg levels. The number of newborns will also peak in 2045 (United Nations, https://population.un.org), which helps to the level off of total avoided IQ decrements (Figure 5A). The avoided economic loss continues to increase after 2050, however, due to the continuous increase in income level (Figure $5 B)$. 

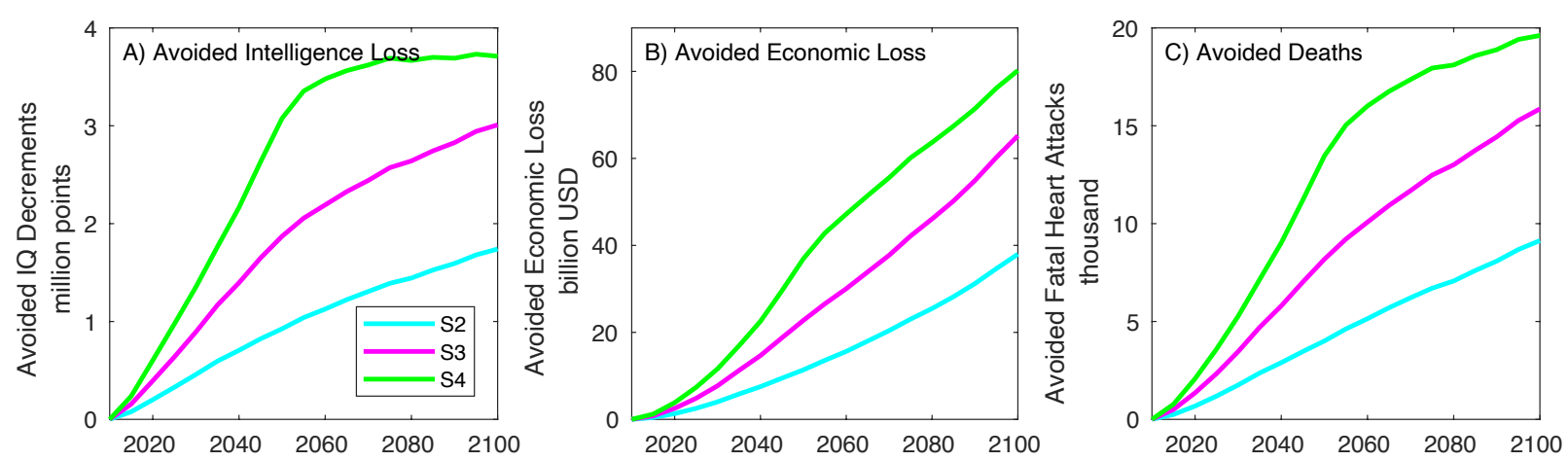

Figure 5. Trajectories of global annual human health benefits associated with different emission scenarios of the Minamata Convention. A) Avoided IQ decrements of newborns; B) Avoided economic loss from IQ decrements of newborns (before discounted), and C) Avoided fatal heart attacks.

Limitations. We adopt so far the most comprehensive approach to model the food $\mathrm{MeHg}$ concentrations, especially the inclusion of ocean model coupled with plankton ecosystem is of great interest because seafood consumption is the major exposure pathway in most countries (Eagles-smith et al. 2018; Sunderland, Li, and Bullard 2018a). Our ability to model the MeHg risk is limited by existing scientific knowledge and data, such as the food web dynamics of $\mathrm{MeHg}$ in higher trophic levels. The fishery harvest and human food consumption patterns will also change in the future. Our results do not show strong interannual variability on a global scale, but the change in dietary structure and food web dynamics in high trophic levels that are not covered in this model may amplify these variabilities, especially at regional scales. The permafrost stores a large amount of $\mathrm{Hg}$ and may serve as a potential $\mathrm{Hg}$ source as a consequence of thawing (Schuster et al. 2018). There are likely other health endpoints not considered in this study due to the limited epidemiological data (Karagas et al. 2012). Our assessment is considered illustrative and the uncertainty of the model framework could be reduced as science evolves.

Policy implications. This study illustrates a comprehensive climate-atmosphere-ocean-ecosystem and exposurerisk model framework, which provides a useful tool for parties to evaluate the effectiveness of convention implementation, especially to assess the response of environmental $\mathrm{Hg}$ levels to emission reduction and its implications to human exposure and health risk. This, in turn, helps parties to define emission control technological options and to advance phaseout dates of related activities. With the future improvement of spatial resolution in exposure and risk modeling, our model could also be a useful tool to identify populations that are vulnerable to $\mathrm{Hg}$ exposure.

Our projections indicate substantial global human health costs if delaying emission reduction actions. Although a systematic cost-benefits of implementing the Convention is beyond the scope of this study, our results generally demonstrate the necessity of action sooner. Detailed scenario studies using our model framework could be conducted to evaluate and prioritize the health benefits of individual policy measures. For example, closure of $\mathrm{Hg}$ mines and phase-out of $\mathrm{Hg}$ use in products and several industrial processes have started or will start in several years, and the best available technique and best environmental practice for fossil fuel combustion will be implemented soon. As the largest emission source, the control of ASGM, however, is left decided for individual parties and the future emissions have large uncertainty. Our framework would be an ideal testbed for related countries to make their national action plans. 
Contrasting with previous thought that a linear relationship exists between emission and ingestion (e.g. Spadaro and Rabl 2008), we show that the marginal benefits of anthropogenic emission reductions will decrease substantially after 2050. On top of the decreasing anthropogenic emissions, our results illustrate the importance of climate and environment changes, $\mathrm{Hg}$ cycling, population dietary choice, and social-economic parameters (e.g. birth numbers and per-capita income) in $\mathrm{Hg}$ risk and benefit assessment.

\section{Methods}

Mercury transport model. We develop a model framework to simulate the fate and transport of $\mathrm{Hg}$ in the Earth system that includes climate, atmosphere, land, ocean, and marine ecosystem (Figure S1). Three-dimensional atmospheric (GEOS-Chem) and oceanic (MITgcm) transport models for $\mathrm{Hg}$ are coupled online with a twodimensional terrestrial mercury model. These models are driven by predicted meteorological and ocean circulation data from climate models (GISS GCM ModelE2 and IGSM). Biogeochemical parameters important for mercury transformation are taken from a marine plankton ecosystem model (Darwin), which is also driven by the IGSM model. The details of these models are elaborated below.

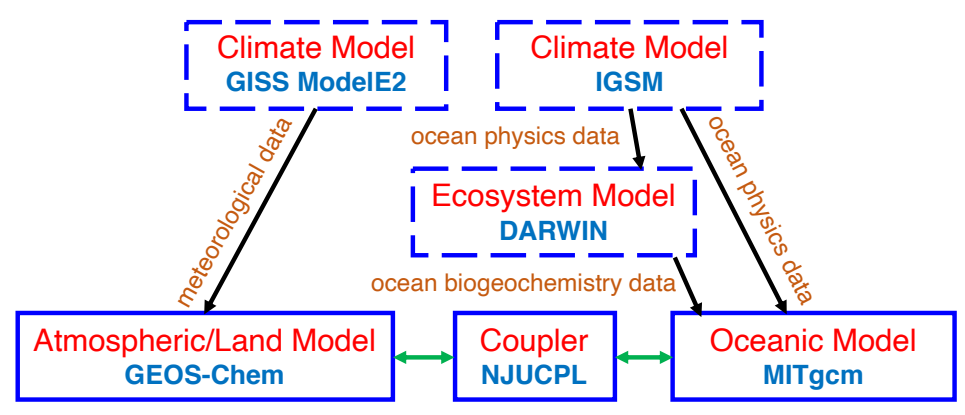

Figure 6. The model framework used in this study. Blue boxes represent models while arrows indicate data flows. Models with dashed boxes are run by previous studies and we directly use their archived output, while those with solid lines are run in this study. Black arrows mean feeding of archived data from one model to another (i.e. models are run separately), while green arrows mean running two models simultaneously with online data exchange.

We use the output of the Integrated Global System Modeling (IGSM) framework for the future climate simulated by Sokolov et al. (2009) and Dutkiewicz et al. (2013). Briefly, the model framework includes a threedimensional ocean model that has a horizontal resolution of $2^{\circ} \times 2.5^{\circ}$ and 22 vertical levels from $10 \mathrm{~m}$ in the surface to $500 \mathrm{~m}$ at depth, and a two-dimensional (latitude and height) atmosphere physical and chemical model. The framework has a terrestrial component with hydrology, vegetation, and natural emissions. The model is run with a pre-industrial level of greenhouse gas concentration for 2000 years as spin up and then for 1860-2000 with observed GHG levels. For the $21^{\text {st }}$ century, a 'business as usual' scenario (close to IPCC AR5 RCP8.5 scenario) is assumed for anthropogenic emissions. Here we use the IGSM only for the ocean changes and use the archived monthly mean ocean physics data such as seawater temperature, ocean current velocities and mixing conditions to drive the MITgcm model(Stephanie Dutkiewicz et al. 2013).

As the IGSM only contains a two-dimensional atmosphere module, we use the archived future climate data simulated by the NASA Goddard Institute for Space Studies (GISS) general circulation model (GCM) (ModelE2) 
to drive the GEOS-Chem model(Rind et al. 2007). The model has a horizontal resolution of $2^{\circ} \times 2.5^{\circ}$ for the atmosphere, land surface, ocean, and sea ice models. The three-dimensional atmosphere model has 40 vertical levels from the surface to $0.002 \mathrm{hpa}$ ( $\sim 85 \mathrm{~km}$ altitude). The greenhouse gas concentrations are specified following the IPCC AR5 RCP8.5 scenario. The meteorology fields such as temperature and precipitation are archived with a frequency of 3-6 hours. The discrepancies between these two climate models are minimal due to the similar pathways of greenhouse gas concentrations in the $21^{\text {st }}$ century.

The ocean biogeochemistry and ecosystem data are from the Darwin model within the MITgcm framework simulated by Dutkiewicz et al. during the $21^{\text {st }}$ century (Stephanie Dutkiewicz et al. 2013). This model is driven by the archived ocean physics fields from the IGSM. The transport of inorganic and organic forms of carbon, nitrogen, phosphorus, iron, and silica are included. The model includes six phytoplankton functional groups and two zooplankton grazers (namely diatoms, other large phytoplankton, diazotroph, coccolithophore, Prochlorococcus, Synechococcus, and small and large herbivorous plankton). The model simulates biogeochemical processes including phytoplankton growth, zooplankton grazing, zooplankton mortality, and the formation and transformation of particulate and dissolved organic matters. The monthly mean concentrations of organic carbon and plankton biomass, and the rates of plankton growth, grazing, and mortality are archived to force the MeHg component of the model.

We simulate the chemistry, transport, and trophic transfer of mercury in the ocean using the MIT General Circulation Model (MITgcm) following Y. Zhang et al. (2020). The model is driven by ocean physics data from the IGSM and biogeochemical parameters from the Darwin model. The model has the same grid as the ocean component of the IGSM. The model simulates 14 tracers that include elemental mercury, oxidized mercury, monomethylmercury, dimethylmercury, particulate-bound inorganic mercury and monomethylmercury, and monomethylmercury in plankton (six phytoplankton groups and two zooplankton types). The model includes a detailed photo- and biological mediated redox chemistry of inorganic mercury, and the transformation with methylated $\mathrm{Hg}$ species $(\mathrm{MeHg})$. The bioaccumulation and biomagnification of monomethylmercury in the marine plankton food web is simulated following Y. Zhang et al. (2020).

The atmospheric chemistry and transport of mercury are simulated by the GEOS-Chem model following Y. Zhang et al. (2016). The model is based on version v9-02 (www.geos-chem.org). The model has the same resolution as the GISS GCM ModelE2 model and is driven by its archived meteorology fields. The simulated chemistry includes three forms of mercury in the atmosphere: gaseous elemental, gaseous oxidized, and particlebound mercury. The redox chemistry of mercury is modeled following Horowitz et al. (2017). The chemistry includes two-stage oxidation of elemental mercury by bromine atoms and photoreduction of oxidized mercury in cloud droplets. Concentrations of related chemical species are taken from GEOS-Chem simulation of tropospheric oxidant-aerosol chemistry (Schmidt et al. 2016). The soil pool and land-atmosphere exchange of mercury are modeled following Selin et al. (N. E. Selin et al. 2008) and Smith-Downey et al. (2010). The model also includes geogenic and biomass burning sources, as well as reemissions from snow reservoirs (Horowitz et al. 2017).

The GEOS-Chem and MITgcm mercury models are online two-way coupled using a coupler (NJUCPL) following Y. Zhang et al. (2019). With a frequency of 60 mins, atmospheric Hg concentration and deposition data are passed from GEOS-Chem to MITgcm, and ocean evasion flux is passed from MITgcm to GEOS-Chem. 
The initial conditions of these models are taken from previous simulations for the present-day (Horowitz et al. 2017; Stephanie Dutkiewicz et al. 2013; Y. Zhang et al. 2020).

The total anthropogenic $\mathrm{Hg}$ emissions for the future are taken from Pacyna et al. (2016). Four policy scenarios are developed with different assumptions for how fast the emission reduction targets are achieved (N. E. Selin 2018) (Figure 1): the first scenario S1 is treated as a baseline with close to a constant emission: 1890 $\mathrm{Mg} \mathrm{year}^{-1}$ in 2100; slightly increased to $1960 \mathrm{Mg}$ year $^{-1}$ in 2035 then kept unchanged to 2100; S2: linear reduction to $1020 \mathrm{Mg}$ year $^{-1}$ by 2100 ; S3: linear reduction to $1020 \mathrm{Mg}$ year $^{-1}$ by 2050 and $300 \mathrm{Mg}$ year $^{-1}$ by 2100; S4: linear reduction to $1020 \mathrm{Mg} \mathrm{year}^{-1}$ by $2035,300 \mathrm{Mg}$ year $^{-1}$ by 2050 , and close to zero emissions by 2100. These global total emissions are spatially distributed to each model grid based on the WHET emission inventory for 2010 (Y. Zhang et al. 2016). The spatial distribution and speciation of mercury emissions are assumed to keep constant during the model period. The model is run from 2010 to 2100 for each emission scenario.

Mercury exposure modeling. Figure S2 summarizes the approach we use to estimate MeHg exposure and risk. The MeHg exposure via food is considered in this study and is divided into two categories: seafood and food produced on land (rice and freshwater fish, other types of food are ignored because of much lower $\mathrm{MeHg}$ concentrations). The per-capita consumption of different food categories for each country is taken from the database of the Food and Agriculture Organization of the United Nations (UN FAO, http://www.fao.org). For the seafood, we assume the estimated daily intake of $\mathrm{MeHg}$ (EDI, $\mathrm{n} \mathrm{kg}^{-1} \mathrm{~d}^{-1}$ ) of each country for a given year (2010-2100) is proportional to its seafood consumption (FOOD ${ }^{\text {seafood }}, \mathrm{kg} \mathrm{y}^{-1}$ ) scaled by the global average plankton MeHg concentrations weighted by the spatial distribution of fish harvest ( $\left.\mathrm{MeHg}^{\text {plankton }}\right)$ (Watson 2017):

$$
E D I_{\text {year }}^{\text {seafood }}=F O O D^{\text {seafood }} \times \frac{E D I_{\text {ref }}^{\text {seafood }}}{F O O D_{\text {ref }}^{\text {seafood }}} \times \frac{M e H g_{\text {year }}^{\text {planton }}}{M e H g_{2010}^{\text {plankton }}}
$$

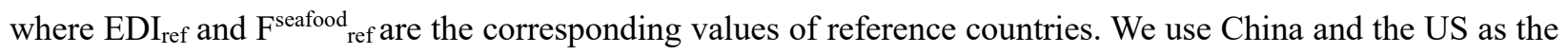
reference countries (Sunderland, Li, and Bullard 2018b; Chen et al. 2019).

Similarly, we calculate the $\mathrm{MeHg}$ intake from food produced on land for each country for a given year based on its food consumption (FOOD ${ }^{\text {type }}, \mathrm{kg} \mathrm{y}^{-1}$; type = rice and freshwater fish). Due to the lack of data, the food consumption pattern is held constant in the $21^{\text {st }}$ century. The MeHg concentrations in these foods are assumed to be proportional to the average total mercury atmospheric deposition weighted by population (DEP, $\mu \mathrm{g} \mathrm{m}^{-2} \mathrm{y}^{-1}$ ) following Giang and Selin(Giang and Selin 2016) and Chen et al. (2019):

$$
E D I_{\text {year }}^{\text {land food }}=\sum_{\text {type }} F O O D^{\text {type }} \times \frac{E D I_{\text {ref }}^{\text {type }}}{F O O D_{\text {ref }}^{\text {type }}} \times \frac{D E P_{\text {year }}}{D E P_{2010}^{\text {ref }}}
$$

where China is chosen as the reference country as it is the only country with a comprehensive evaluation of exposure risk from a variety of food types(Chen et al. 2019). We exclude food $\mathrm{MeHg}$ concentration data for contaminated sites. The total EDI is calculated as the sum of EDI ${ }^{\text {seafood }}$ and EDI ${ }^{\text {land food }}$. 


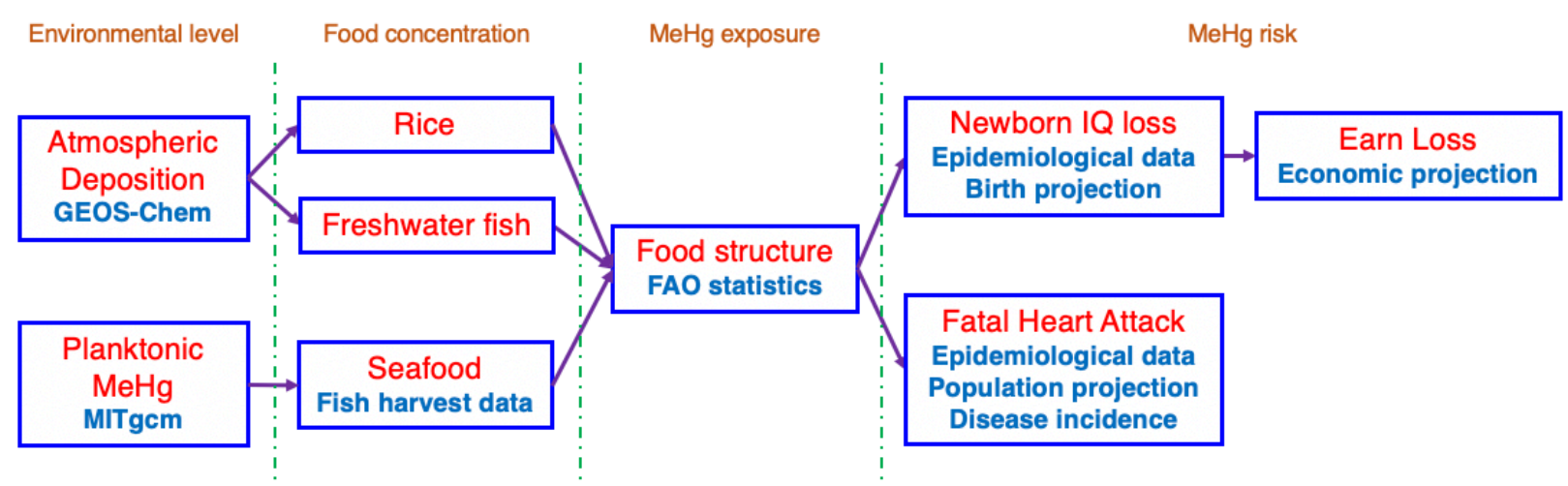

Figure 7. Diagram for the approach and data sources for MeHg exposure and risk calculation in this study.

Human health impact. We include two health endpoints in benefit estimates: decrement in IQ of newborns and fatal heart attack (Rice, Hammitt, and Evans 2010; Giang and Selin 2016; Chen et al. 2019). A linear doseresponse relationship without thresholds is recommended by the National Research Council (NRC) between MeHg intake and fetal IQ decrements (Axelrad et al. 2007):

$$
\Delta I Q=\gamma \lambda \beta \times \Delta E D I \times B W
$$

where $\Delta I Q$ is the changes in IQ (points), $\triangle E D I$ is the changes in $E D I$ of $\mathrm{MeHg}$, and $B W$ is the average body weight for female adults. The coefficients $\beta\left(0.6 \mu \mathrm{g} \mathrm{L}^{-1}\right.$ per $\left.\mu \mathrm{g} \mathrm{day}^{-1}\right), \lambda\left(0.2 \mu \mathrm{g} \mathrm{g}^{-1}\right.$ per $\left.\mu \mathrm{g} \mathrm{L}^{-1}\right)$, and $\gamma(0.3$ IQ points per $\mu \mathrm{g} \mathrm{g}^{-1}$ ) converse from $\mathrm{MeHg}$ intake to blood concentration, blood concentrations to hair concentrations, and hair concentrations to IQ decrements, respectively. The total IQ decrements are calculated by multiplying per-fetus IQ decrements and the number of newborns, which are taken from the World Population Prospects by the UN database (https://population.un.org). This database includes projections of the total population of both sexes and newborns for each country to 2100 . The IQ decrements are converted to monetary values using $\$ 200818,832$ per IQ point normalized by the ratio between the PPP-adjusted GDP per capita in each country and the US(Bellanger et al. 2013). The economic data is taken from the shared socioeconomic pathways database that projects the GDP growth for each country in the $21^{\text {st }}$ century (https://tntcat.iiasa.ac.at/SspDb). We use the SSP2 scenario that assumes a median level of GDP growth rate.

A log-linear dose-response relationship between $\mathrm{MeHg}$ intake and $\mathrm{Hg}$-related fatal heart attacks is used in this study(Chen et al. 2019):

$$
\Delta C F=\sum_{g} P_{g} \times C f_{g} \times \omega \times\left(1-e^{-\varphi \lambda \beta \times \Delta E D I \times B W}\right)
$$

where $\triangle C F$ is the changes in the deaths from fatal heart attacks associated with MeHg exposure, $P_{g}$ is the population of gender $g$ (male and female) from World Population Prospects, and $C f_{g}$ is the age-adjusted incidence of fatal heart attacks of gender $g$ from Global Health Estimates by World Health Organization (http://www.who.int/healthinfo/global_burden_disease). The coefficient $\varphi\left(0.066\right.$ per $\left.\mu \mathrm{g} \mathrm{g}^{-1}\right)$ converses hair $\mathrm{MeHg}$ concentrations to fatal heart attack risks. The subjective coefficient $\omega(0.33)$ represents the probability of the causality of the associations, reflecting the substantial uncertainties due to limited epidemiological studies.

\section{Acknowledgments}


We thank Aijun Ding, Bin Wang, Guoxing Li, Qingru Wu, Lars-Eric Heimbürger, Noelle Selin, and Elsie Sunderland for helpful discussions. The authors gratefully acknowledge financial support from National Natural Science Foundation of China (NNSFC) 41875148, Start-up fund from the Thousand Youth Talents Plan, Jiangsu Innovative and Entrepreneurial Talents Plan, the Collaborative Innovation Center of Climate Change, Jiangsu Province.

\section{Data availability}

All data and model algorithms are available in the Extended Data and Supplementary Information.

\section{Code availability}

All model code is available at the following link: http://ebmg.online/model_hg.html.

\section{References}

AMAP/UNEP. 2013. "Technical Background Report for the Global Mercury Assessment.” Arctic Monitoring and Assessment Programme, 263. http://www.amap.no/documents/doc/technical-background-report-for-theglobal-mercury-assessment-2013/848.

Amos, Helen M., Daniel J. Jacob, David G. Streets, and Elsie M. Sunderland. 2013. "Legacy Impacts of All-Time Anthropogenic Emissions on the Global Mercury Cycle." Global Biogeochemical Cycles 27 (2): 410-21. https://doi.org/10.1002/gbc.20040.

Axelrad, Daniel A., David C. Bellinger, Louise M. Ryan, and Tracey J. Woodruff. 2007. "Dose-Response Relationship of Prenatal Mercury Exposure and IQ: An Integrative Analysis of Epidemiologic Data.” Environmental Health Perspectives 115 (4): 609-15. https://doi.org/10.1289/ehp.9303.

Basu, Niladri, Milena Horvat, David C. Evers, Irina Zastenskaya, Pál Weihe, and Joanna Tempowski. 2018. “A State-of-the-Science Review of Mercury Biomarkers in Human Populations Worldwide between 2000 and 2018." Environmental Health Perspectives 126 (10): 1-14. https://doi.org/10.1289/EHP3904.

Bellanger, Martine, Céline Pichery, Dominique Aerts, Marika Berglund, Argelia Castaño, Mája Čejchanová, Pierre Crettaz, et al. 2013. "Economic Benefits of Methylmercury Exposure Control in Europe: Monetary Value of Neurotoxicity Prevention.” Environmental Health: A Global Access Science Source 12 (1): 1-10. https://doi.org/10.1186/1476-069X-12-3.

Bellinger, David C. 2012. "A Strategy for Comparing the Contributions of Environmental Chemicals and Other Risk Factors to Neurodevelopment of Children." Environmental Health Perspectives 120 (4): 501-7. https://doi.org/10.1289/ehp.1104170.

Blum, Joel D, Brian N Popp, Jeffrey C Drazen, C Anela Choy, and Marcus W Johnson. 2013. "Methylmercury Production below the Mixed Layer in the North Pacific Ocean.” Nature Geoscience 6 (10): 879-84. https://doi.org/10.1038/ngeo1918.

Chen, Long, Sai Liang, Maodian Liu, Yujun Yi, Zhifu Mi, Yanxu Zhang, Yumeng Li, et al. 2019. "Trans-Provincial Health Impacts of Atmospheric Mercury Emissions in China." Nature Communications, 1-12. https://doi.org/10.1038/s41467-019-09080-6. 
Dutkiewicz, S., J. R. Scott, and M. J. Follows. 2013. "Winners and Losers: Ecological and Biogeochemical Changes in a Warming Ocean.” Global Biogeochemical Cycles 27 (2): 463-77. https://doi.org/10.1002/gbc.20042.

Dutkiewicz, Stephanie, J Jeffrey Morris, Michael J Follows, Jeffery Scott, Orly Levitan, Sonya T Dyhrman, and Ilana Berman-frank. 2013. "Impact of Ocean Acidification on the Structure of Phytoplankton Communities," 1-19. https://doi.org/10.1038/NCLIMATE2722.

Eagles-smith, Collin A, Ellen K Silbergeld, Niladri Basu, Paco Bustamante, Fernando Diaz-barriga, William A Hopkins, Karen A Kidd, and Jennifer F Nyland. 2018. "Modulators of Mercury Risk to Wildlife and Humans in the Context of Rapid Global Change." Ambio 47 (2): 170-97. https://doi.org/10.1007/s13280-017-1011-x.

Giang, Amanda, and Noelle E. Selin. 2016. "Benefits of Mercury Controls for the United States." Proceedings of the National Academy of Sciences of the United States of America 113 (2): 286-91. https://doi.org/10.1073/pnas.1514395113.

Grandjean, Philippe, Céline Pichery, Martine Bellanger, and Esben Budtz-Jorgensen. 2012. "Calculation of Mercury’s Effects on Neurodevelopment.” Environmental Health Perspectives 120 (12): A452. https://doi.org/10.1186/1476-069X-11-53.

Griffiths, Charles, Al McGartland, and Maggie Miller. 2007. “A Comparison of the Monetized Impact of IQ Decrements from Mercury Emissions.” Environmental Health Perspectives. https://doi.org/10.1289/ehp.9797.

Horowitz, Hannah M., Daniel J. Jacob, Helen M. Amos, David G. Streets, and Elsie M. Sunderland. 2014. "Historical Mercury Releases from Commercial Products: Global Environmental Implications." Environmental Science and Technology 48 (17): 10242-50. https://doi.org/10.1021/es501337j.

Horowitz, Hannah M., Daniel J. Jacob, Yanxu Zhang, Theodore S. DIbble, Franz Slemr, Helen M. Amos, Johan A. Schmidt, Elizabeth S. Corbitt, Eloïse A. Marais, and Elsie M. Sunderland. 2017. "A New Mechanism for Atmospheric Mercury Redox Chemistry: Implications for the Global Mercury Budget." Atmospheric Chemistry and Physics 17 (10): 6353-71. https://doi.org/10.5194/acp-17-6353-2017.

Karagas, Margaret R., Anna L. Choi, Emily Oken, Milena Horvat, Rita Schoeny, Elizabeth Kamai, Whitney Cowell, Philippe Grandjean, and Susan Korrick. 2012. "Evidence on the Human Health Effects of Low-Level Methylmercury Exposure.” Environmental Health Perspectives. https://doi.org/10.1289/ehp.1104494.

Pacyna, Jozef M., Oleg Travnikov, Francesco De Simone, Ian M. Hedgecock, Kyrre Sundseth, Elisabeth G. Pacyna, Frits Steenhuisen, Nicola Pirrone, John Munthe, and Karin Kindbom. 2016. "Current and Future Levels of Mercury Atmospheric Pollution on a Global Scale." Atmospheric Chemistry and Physics 16 (19): 12495-511. https://doi.org/10.5194/acp-16-12495-2016.

Rice, Glenn E., and James K. Hammitt. 2005. Economic Valuation of Human Health Benefits of Controlling Mercury Emissions from U. S. Coal-Fired Power Plants. Boston, MA, USA.

Rice, Glenn E., James K. Hammitt, and John S. Evans. 2010. “A Probabilistic Characterization of the Health Benefits of Reducing Methyl Mercury Intake in the United States.” Environmental Science and Technology 44 (13): 5216-24. https://doi.org/10.1021/es903359u. 
Rind, D., J. Lerner, J. Jonas, and C. McLinden. 2007. "Effects of Resolution and Model Physics on Tracer Transports in the NASA Goddard Institute for Space Studies General Circulation Models." Journal of Geophysical Research Atmospheres. https://doi.org/10.1029/2006JD007476.

Roman, Henry A., Tyra L. Walsh, Brent A. Coull, Éric Dewailly, Eliseo Guallar, Dale Hattis, Koenraad Mariën, et al. 2011. "Evaluation of the Cardiovascular Effects of Methylmercury Exposures: Current Evidence Supports Development of a Dose-Response Function for Regulatory Benefits Analysis." Environmental Health Perspectives 119 (5): 607-14. https://doi.org/10.1289/ehp.1003012.

Rothenberg, Sarah E, Lisamarie Windham-myers, and Joel E Creswell. 2014. "Rice Methylmercury Exposure and Mitigation : A Comprehensive Review." Environmental Research 133: 407-23. https://doi.org/10.1016/j.envres.2014.03.001.

Schartup, Amina T, P Colin, Asif Qureshi, Clifton Dassuncao, Kyle Gillespie, Alex Hanke, and Elsie M Sunderland. n.d. "Climate Change and Overfishing Increase Neurotoxicant in Marine Predators." Nature. https://doi.org/10.1038/s41586-019-1468-9.

Schmidt, J. A., S. Wang, D. J. Jacob, H. M. Horowitz, L. Hu, T. Sherwen, M. J. Evans, et al. 2016. "Modeling the Observed Tropospheric BrO Background: Importance of Multiphase Chemistry and Implications for Ozone, OH, Andmercury." Journal of Geophysical Research, 1-17. https://doi.org/10.1002/2015JD024229.

Schuster, Paul F., Kevin M. Schaefer, George R. Aiken, Ronald C. Antweiler, John F. Dewild, Joshua D. Gryziec, Alessio Gusmeroli, et al. 2018. "Permafrost Stores a Globally Significant Amount of Mercury." Geophysical Research Letters 45: 1463-71. https://doi.org/10.1002/2017GL075571.

Selin, Henrik. 2014. "Global Environmental Law and Treaty-Making on Hazardous Substances: The Minamata Convention and Mercury Abatement." Global Environmental Politics. https://doi.org/10.1162/GLEP_a_00208.

Selin, Noelle E. 2018. “A Proposed Global Metric to Aid Mercury Pollution Policy.” Science 360 (6389): 607-9. https://doi.org/10.1126/science.aar8256.

Selin, Noelle E, Daniel J Jacob, Robert M Yantosca, Sarah Strode, and Lyatt Jaegle. 2008. "Global 3-D LandOcean-Atmosphere Model for Mercury : Present-Day versus Preindustrial Cycles and Anthropogenic Enrichment Factors for Deposition” 22 (Ii): 1-13. https://doi.org/10.1029/2007GB003040.

Smith-Downey, Nicole V., Elsie M. Sunderland, and Daniel J. Jacob. 2010. "Anthropogenic Impacts on Global Storage and Emissions of Mercury from Terrestrial Soils: Insights from a New Global Model.” Journal of Geophysical Research: Biogeosciences 115 (3): 1-11. https://doi.org/10.1029/2009JG001124.

Sokolov, A. P., P. H. Stone, C. E. Forest, R. Prinn, M. C. Sarofim, M. Webster, S. Paltsev, et al. 2009. "Probabilistic Forecast for Twenty-First-Century Climate Based on Uncertainties in Emissions (without Policy) and Climate Parameters." Journal of Climate. https://doi.org/10.1175/2009JCLI2863.1.

Spadaro, Joseph V., and Ari Rabl. 2008. "Global Health Impacts and Costs Due to Mercury Emissions.” Risk Analysis 28 (3): 603-13. https://doi.org/10.1111/j.1539-6924.2008.01041.x. 
Sunderland, Elsie M., Miling Li, and Kurt Bullard. 2018a. "Decadal Changes in the Edible Supply of Seafood and Methylmercury Exposure in the United States.” Environmental Health Perspectives 126 (2): 029003. https://doi.org/10.1289/EHP3460.

. 2018b. "Erratum: 'Decadal Changes in the Edible Supply of Seafood and Methylmercury Exposure in the United States.” Environmental Health Perspectives 126 (2): 029003. https://doi.org/10.1289/EHP3460.

Sunderland, Elsie M, David P Krabbenhoft, John W Moreau, Sarah A Strode, and William M Landing. 2009. "Mercury Sources , Distribution, and Bioavailability in the North Pacific Ocean : Insights from Data and Models" 23 (Ii): 1-14. https://doi.org/10.1029/2008GB003425.

Trasande, Leonardo, Philip J. Landrigan, and Clyde Schechter. 2005. "Public Health and Economic Consequences of Methyl Mercury Toxicity to the Developing Brain." Environmental Health Perspectives. https://doi.org/10.1289/ehp.7743.

Wang, Feiyue, Peter M. Outridge, Xinbin Feng, Bo Meng, Lars Eric Heimbürger-Boavida, and Robert P. Mason. 2019. "How Closely Do Mercury Trends in Fish and Other Aquatic Wildlife Track Those in the Atmosphere? - Implications for Evaluating the Effectiveness of the Minamata Convention." Science of the Total Environment. https://doi.org/10.1016/j.scitotenv.2019.04.101.

Watson, Reg A. 2017. "Data Descriptor : A Database of Global Marine Commercial, Small-Scale, Illegal and Unreported Fi Sheries Catch 1950 - 2014,” 1-9.

Zhang, H, C D Holmes, and S Wu. 2016. "Impacts of Changes in Climate, Land Use and Land Cover on Atmospheric Mercury” 141: 230-44. https://doi.org/10.1016/j.atmosenv.2016.06.056.

Zhang, Hua, Xinbin Feng, Thorjørn Larssen, Guangle Qiu, and Rolf D. Vogt. 2010. "In Inland China, Rice, Rather than Fish, Is the Major Pathway for Methylmercury Exposure." Environmental Health Perspectives 118 (9): 1183-88. https://doi.org/10.1289/ehp.1001915.

Zhang, Yanxu, Hannah Horowitz, Jiancheng Wang, Zhouqing Xie, Joachim Kuss, and Anne L. Soerensen. 2019. "A Coupled Global Atmosphere-Ocean Model for Air-Sea Exchange of Mercury: Insights into Wet Deposition and Atmospheric Redox Chemistry." Research-article. Environmental Science and Technology 53 (9): 5052 61. https://doi.org/10.1021/acs.est.8b06205.

Zhang, Yanxu, Daniel J. Jacob, Hannah M. Horowitz, Long Chen, Helen M. Amos, David P. Krabbenhoft, Franz Slemr, Vincent L. St. Louis, and Elsie M. Sunderland. 2016. "Observed Decrease in Atmospheric Mercury Explained by Global Decline in Anthropogenic Emissions." Proceedings of the National Academy of Sciences of the United States of America 113 (3): 526-31. https://doi.org/10.1073/pnas.1516312113.

Zhang, Yanxu, Anne L Soerensen, Amina T Schartup, and Elsie M Sunderland. 2020. "A Global Model for Methylmercury Formation and Uptake at the Base of Marine Food Webs." Global Biogeochemical Cycles 34: 1-44. https://doi.org/10.1029/2019GB006348. 